\title{
El lenguaje abismal. La mística del lenguaje en Walter Benjamin
}

\author{
Emiliano Mendoza Solís
}

Walter Benjamin expone en su ensayo de juventud denominado "Sobre el lenguaje en cuanto tal y sobre el lenguaje del hombre" (1916), los aspectos más importantes relativos a la teoría del lenguaje. La idea de lenguaje está fundamentada mediante el examen de los contenidos espirituales del hombre y su relación con el ser lingüístico. Esta distinción condiciona a la teoría a permanecer sobre el abismo que anida en el interior de la entidad espiritual del lenguaje. El elemento abismal da lugar a una revelación o principio (arché) vinculado a la mística del lenguaje.

PALABRAS ClAVE: Walter Benjamin, lenguaje, mística, abismo.

In his early essay On Language as such and on the Language of Man (1916) Benjamin states the most important aspects related to a theory of language. His idea of language is based on the examination of the spiritual contents of man and his relation with his linguistic self. This distinction leads the theory to remain on the abyss that nests in the interior of the spiritual entity of language. The abyss element brings about a revelation or a principal (arché) related to the mysticism of language.

KEYWORDS: Walter Benjamin, language, mystic, abyss.

Fecha de recepción: 30 de julio de 2013

Fecha de aceptación: 2 de septiembre de 2013 

Emiliano Mendoza Solís

Universidad Nacional Autónoma de México

Universidad Michoacana de San Nicolás de Hidalgo

\section{EI lenguaje abismal.}

\section{La mística del lenguaje en Walter Benjamin}

La teoría no puede referirse nunca a lo real, pero en cambio tiene que estar en relación con el lenguaje.

W. BENJAMIN

Vivimos en el interior de nuestra lengua semejantes, la mayoría de nosotros, a ciegos que caminan sobre un abismo.

G. SCHOLEM

En una carta dirigida a Hugo von Hofmannsthal en 1924, Benjamin expone, valiéndose de una imagen arquitectónica, el impulso que guía toda "tentativa" literaria en su obra. Benjamin sabe lo que el tema del lenguaje, y particularmente el lenguaje lírico, significa para su interlocutor, quien con el tiempo se convertirá también en una especie de mentor. Esta carta no trata de ninguna crisis vocacional o existencial cuyos efectos trastoquen los cimientos de una idea de lenguaje como es el caso de ese extraordinario testimonio de renuncia a la lírica que es $L a$ carta al Lord de Chandos, redactada por Hofmannsthal a principios del siglo xx. En este caso Benjamin expone una noción de lenguaje donde este se presenta como una especie de suelo nutricio para toda expresión 
o reflexión literaria y científica, una convicción cuya certidumbre radica en percibir

que cada verdad tiene su sitio, su palacio ancestral, en el lenguaje, que este palacio se construyó con los más antiguos logoi, y que, comparada con una verdad así fundamentada, la percepción de la ciencia permanecerá inferior mientras, por así decirlo, irá pasando como nómada de aquí para allá por el terreno del lenguaje, convencida de que este consiste en signos, una convicción que origina la arbitrariedad irresponsable de su terminología (Gesammelte Briefe, I, 392).

La ciencia, según la idea de Benjamin, desfallece al referirse a lo real y pierde toda relación respecto al propio lenguaje. De manera que el vínculo más importante de toda teoría científica no debe buscarse ingenuamente en relación a una idea de realidad dada, sino respecto al lenguaje. Entonces, tomando como elemento orientador tal preeminencia del lenguaje es preciso cuestionar: ¿en qué consiste la idea del lenguaje de Benjamin y qué medios emplea para vincularse con esos antiguos logoi que habitan en el interior del palacio ancestral? ¿Cómo articular una teoría que no pierda contacto con el logos que le da lugar y la contiene?

El estado general de estas interrogantes es analizado en primera instancia en el conocido ensayo de 1916, "Sobre el lenguaje en cuanto tal y sobre el lenguaje del hombre". Se trata de un texto que tiene que analizarse como un borrador, como una especie de programa rudimentario y hermético en el que Benjamin recoge sus impresiones de lecturas y conversaciones con Gershom Scholem sobre filosofía del lenguaje. Se trata de un texto que Benjamin no vio publicado, cuyo primer objetivo era continuar por escrito las discusiones con Scholem sobre la esencia del lenguaje. ${ }^{1}$ Sin embargo, lo expuesto en este esbozo de manera sinóptica, tiene continuidad en el corpus de toda su obra. De manera preliminar hay que mencionar dos aspectos generales de la idea de lenguaje de Benjamin. En primer lugar, se trata de una advertencia hecha por el propio Scholem al referirse a Benjamin como "un puro místico de

\footnotetext{
${ }^{1}$ Benjamin consideró este escrito la primera de tres partes, siendo esta versión la única de la que hay testimonio. Cfr. G. Scholem, Historia de una amistad, 48.
} 
la lengua" (Lenguajes y cábala, 14), esto es, como un autor cuya orientación parte de reconocer que el "lenguaje, el medio en el que se desarrolla la vida espiritual de los hombres, posee una cara interna" (12). En el lenguaje prevalece una instancia más allá de las relaciones de comunicación entre los seres: "el hombre se comunica, busca hacerse comprensible para los demás, pero en todos esos intentos late algo que no es tan solo signo, comunicación, significado y expresión" (12). Esta cara interna permanece oculta en la parte más común de la lengua como lo es la voz que da sonoridad y forma, pues todo ello, desde el primer momento, muestra más de lo que toda comprensión puede contener. En este sentido la cuestión más importante para Benjamin no es otra sino la de cualquier místico de la lengua: develar en qué consiste esta cara interna, tras lo cual la tarea filosófica radicará en mostrar cómo se constituye y configura el carácter simbólico de la lengua.

La segunda observación previa tiene que ver con la idea de teoría en general y de teoría del lenguaje en particular. Para Benjamin el alcance de cualquier postura filosófica depende de la teoría del lenguaje. Por ejemplo, en otro texto programático de juventud, este de 1917, concebido a partir del pensamiento de Kant, nos dice:

por encima de la conciencia de que el conocimiento filosófico es absolutamente determinado y apriorístico, por encima de la conciencia de los sectores de la filosofía de igual extracción que las matemáticas, está para Kant el hecho de que el conocimiento filosófico encuentra su única expresión en el lenguaje y no en fórmulas o números. Y este hecho viene a ser decisivo para afirmar en última instancia la supremacía de la filosofía por sobre todas las ciencias, incluidas las matemáticas. El concepto resultante de la reflexión sobre la entidad lingüistica del conocimiento creará un correspondiente concepto de experiencia, que convocará además ámbitos cuyo verdadero ordenamiento sistemático Kant no logró establecer. Y la religión es el de mayor envergadura entre estos últimos ("Sobre el programa de la filosofía venidera", 84. Énfasis mío).

De la reflexión sobre el lenguaje depende la concepción de la experiencia y el reordenamiento sistemático de todo el pensamiento, y dentro de ese nuevo orden la religión tendrá, necesariamente, que asumir su protagonismo. En ello reside la dificultad teórica de la cuestión: la 
tarea de toda teoría del lenguaje, y con ello de toda teoría en general en la medida que se encuentran anclada al lenguaje, no es otra que permanecer sobre el abismo. En la carta a Hofmannsthal el lenguaje aporta el "terreno" donde los palacios ancestrales del conocimiento hunden sus cimientos mientras las teorías científicas del lenguaje vagan errantes tratando vanamente de descifrar el saber a través de signos (fórmulas y números); en el texto de 1916, la errancia de la teoría es representada en su elemento abismal, algo "suspendido" sobre un abismo cuya "topografía" no es otra que el espacio del ser espiritual de las cosas: "entendida como hipótesis, la idea de que el ser espiritual de una cosa consiste en su lenguaje es el gran abismo en el que toda teoría del lenguaje amenaza caer, y la tarea de la teoría del lenguaje consiste en mantenerse sobre él suspendida" ("Sobre el lenguaje en cuanto tal”, 146. Énfasis mío).

Suspendida sobre el abismo (Abgrund) la plausibilidad de la teoría del lenguaje depende, entonces, de una especie de trabajo de equilibrismo. Ante ello ¿cómo fundamentar, cómo encontrar fundamento (Grund) a una teoría que pervive suspendida sobre el abismo (Abgrund)? Lo designado por el propio Benjamin como tarea (Aufgabe) de la teoría del lenguaje, consiste en persistir suspendida sobre el abismo, suponiendo que la teoría permita "ver", pueda dar alguna estructura a la cara interna de la lengua y con ello expresar lo inexpresable. La tarea de la teoría no es otra sino concebir sus posibilidades para acceder al terreno místico de la lengua, ahí donde está su fundamento, en el fondo imposible del abismo. Ahora bien, no perdamos de vista que si la plausibilidad de toda teoría del lenguaje, o del conocimiento, está suspendida sobre el abismo, esto se debe a que Benjamin ha tomado la determinación de concebir el lenguaje como "ser espiritual". Una clave para esclarecer la paradoja inherente al ser abismal del lenguaje queda formulada mediante el tema de la secularización de la lengua que se alcanza a entrever en los pasajes antes mencionados. Cuando Benjamin reformula el problema del lenguaje a través del pensamiento kantiano como la reflexión sobre la entidad lingüística del conocimiento que tiene que aportar un nuevo concepto de experiencia, y con ello reordenar sistemáticamente los demás ámbitos de lo humano, está pensando principalmente en el olvido de la religión operado desde el pensamiento ilustrado, esto es, el olvido de un ámbito de la "mayor envergadura" entre los que han 
quedado fuera del sistema kantiano. Antes de formular una dialéctica de la secularización, es decir, una dialéctica cuyo eje principal es la interacción entre lo sagrado y lo profano en el lenguaje, Benjamin parte de un paradigma puramente teológico. En el escrito de 1916 encontramos la descripción de un proceso de decadencia, o dicho en sus términos, la descripción de una caída al elemento abismal a través de la cual se pueden detectar tres etapas en la historia bíblica del Génesis claramente identificables, tal como lo muestra Stéphane Mosès:

En la primera, la palabra divina aparece como creadora (Gen. I, 1-21), designa el lenguaje en su esencia original, coincidiendo perfectamente con la realidad que designa. En este nivel primordial, al que el hombre no tuvo ni tendrá nunca acceso, la dualidad de la palabra y de la cosa no existe todavía; el lenguaje es, en su esencia misma, creador de realidad. En la segunda etapa, según el relato bíblico (Gen. II, 18-24), Adán da nombre a los animales. Este acto de nominación funda el lenguaje original del hombre, hoy perdido, pero cuyos ecos permanecen para nosotros a través de la función simbólica, es decir poética del lenguaje. Lo que lo caracteriza es la coincidencia perfecta de la palabra y de la cosa que designa. En esta fase, lenguaje y realidad ya no son idénticos, pero existe entre ellos una especie de armonía preestablecida: la realidad es totalmente transparente al lenguaje, el lenguaje abarca, con una precisión casi milagrosa, la esencia misma de la realidad. En la tercera etapa, el "lenguaje paradisiaco", dotado de un poder mágico para poner nombre a las cosas, se pierde y se degrada hasta convertirse en simple instrumento de comunicación. Benjamin, que interpreta aquí el relato del pecado original (Gen. II, 25-III, 24) a la luz del episodio de la torre de Babel (Gen. XI, 1-9), ve en la función comunicativa del lenguaje el signo de su decadencia (El ángel de la historia, 88).

En efecto, estos tres momentos que van de la palabra divina, a la nominación adánica como función simbólica y a la función comunicativa, que da pie finalmente a la instrumentalización de la lengua, se encuentran como telón de fondo en la descripción benjaminiana. El lenguaje termina cayendo irremediablemente en el "abismo de la charlatanería". Después de la inminente pérdida del vínculo original entre la palabra y la cosa, el lenguaje solo se aproxima infructuosamente, limitándose a una especie de "sobredenominación". En este contexto de incertidum- 
bre, puede hablarse de una preeminencia del "lenguaje secularizado" cuya carencia no radica necesariamente en la pobreza del lenguaje comunicativo; por el contrario, es demasiado rico pero se encuentra limitado a su función "instrumentalizadora" tras lo cual la naturaleza queda relegada al mutismo y la desolación, y la palabra adánica permanece como testimonio ciego ante la presencia de una dimensión simbólica de la lengua en espera de algo, o de alguien, que actualice su potencia poética. ${ }^{2}$ Otro proceso bien distinto es el que se da respecto al paradigma del lenguaje y la teología en La tarea del traductor (1923). Mientras el escrito del 1916 está centrado principalmente en el proceso de decadencia, el texto sobre la traducción describe un proceso ascendente hacia la realización utópica. Podría decirse que en este caso el punto de partida es la secularización radical de las lenguas, es decir, un contexto de paroxismo donde es latente la decadencia en el interior del lenguaje, en la que se expresa la corrupción de la condición humana después de la caída y desde ahí se esboza un movimiento de vuelta hacia la perfección perdida. En términos históricos, la degradación del lenguaje está expuesta de manera ascendente, lo cual coincide con su purificación progresiva, es decir, con el proceso de restauración del lenguaje adánico. Benjamin regresa a la diferencia entre el aspecto comunicativo y el aspecto simbólico del lenguaje, estableciendo un paralelismo con otra

${ }^{2}$ Esta incertidumbre queda igualmente expresada a través del conflicto entre experiencia y naturaleza posterior a la catástrofe de Babel: antes de la caída la mudez de la naturaleza era nombrada por el hombre sin romper el vínculo con la divinidad. Después de la caída comienza otra mudez, y con ello la profunda tristeza de la naturaleza. Esta ruptura constituye para Benjamin una verdad metafísica en la medida que es ahí donde cobra sentido la experiencia humana, tanto la del poeta como la del resto de los hombres, quienes al escuchar el lamento natural, son testigos de su tristeza. Ante esto el hombre puede redimir la materia mediante el lenguaje, puede conjurar el lamento de la naturaleza cuya expresión, indiferenciada e impotente, contiene poco más que el aliento sensible. Estos "poderes" del hombre se actualizan tras una experiencia simbólica: escuchar el susurro de las hojas es lo mismo que escuchar un lamento, aquello que se lamenta comienza a ser conocido cuando es escuchado, y al ser nombrado abandona la indiferencia. Sin embargo, recibir un nombre no mengua del todo la tristeza muda de la materia, pues lo que nombra ha dejado de hacerlo en la lengua paradisiaca de los nombres, solo puede hacerlo mediante las lenguas dispersas tras la caída, cuando estas se han multiplicado y los nombres han perdido parte de su viveza. El simbolismo muestra, mediante este proceso, la precariedad irresoluble de la experiencia humana después de la caída y los vínculos infinitos entre naturaleza y hombre. 
oposición, la del acto de significar y la forma de significar. En el lenguaje comunicativo, la intención del locutor está centrada en el acto de significar, en el acontecimiento del mensaje que pretende transmitir. En el uso simbólico del lenguaje, por el contrario, se insiste en la "forma de significar", es decir, en lo que hoy llamaríamos el significante (Mosès, El ángel de la historia, 89). En el caso del texto sobre la traducción, las implicaciones teóricas no son del todo distintas a lo expuesto de manera general sobre este tema en 1916, cuando ya se advierte en la traducción una instancia ascendente aportadora de conocimiento.

Hasta el momento hemos mencionado dos aspectos determinantes en la orientación de la idea de lenguaje de Benjamin: la noción de un lenguaje mágico y la fundamentación de una teoría condicionada a permanecer suspendida sobre el abismo del ser espiritual del lenguaje. Posteriormente se ha mencionado la triada sustraída del Génesis bíblico, mediante la cual queda bien expuesta la presencia de la teología en la idea de lenguaje de Benjamin en el texto de 1916. El proceso decadente, la caída descrita ahí, contrasta con lo descrito en "La tarea del traductor" donde impera un proceso ascendente cuyo objetivo es la consecución de conocimiento, que a su vez es la vía para acceder a la idea de Dios. Sin embargo, ya en la primera exposición programática de Benjamin relativa a la teoría del lenguaje, es decir la de 1916, se ha logrado dilucidar, aunque parcialmente, el papel de la traducción y sus efectos sobre la idea de conocimiento. Como lo observa Stéphane Mosès, la trama teológica de la caída está presente como una especie de telón de fondo frente al que aparecen una serie de ideas y conceptos, los cuales establecen cada uno a su manera, cierta tensión respecto al entramado teológico. Ello da un carácter especialmente programático a la exposición benjaminiana. En las siguientes páginas abordaremos cuatro aspectos o enunciados inherentes a lo expuesto por Benjamin en el texto de 1916. El punto de partida radica en una distinción que nos remite a la ya mencionada idea de ser espiritual frente al ser lingüístico, seguido de los temas consagrados a la comunicación; el hombre y el nombrar, y finalmente, el tema relativo a la gradación y revelación. ${ }^{3}$ Definitiva-

\footnotetext{
${ }^{3}$ A estos cuatro aspectos enunciados en el escrito de 1916, es posible agregar otros tres más como lo son el concepto de traducción, el lenguaje del arte y la simbólica
} 
mente el programa de Benjamin no se limita a estos cuatro temas, pero a partir de estos puede exponerse de qué manera queda articulado el arché del pensamiento benjaminiano. ¿A qué nos referimos con esto? Evidentemente el lenguaje se presenta preeminentemente como un elemento espiritual, como el suelo nutricio de todo conocimiento científico. Todo ello se resuelve en un principio fundamentalmente teológico, en una revelación cuyo contenido de verdad no es expresable mediante proposiciones lingüísticas sobre lo existente, sino en relación a algo centrado en el hecho mismo del ser del lenguaje y del conocimiento. En este sentido cobra pleno valor la revelación, en la medida que la verdad concerniente al lenguaje consiste en que el hombre revela lo existente a través de él, pero no revela el leguaje en cuanto tal. Esto ha sido definido claramente por Giorgio Agamben en los siguientes términos: "el hombre ve el mundo a través del lenguaje, pero no ve el lenguaje. Esta invisibilidad del revelante en aquello que él revela es la palabra de Dios, es la revelación" (La potencia del pensamiento, 29). Extraña contradicción en tanto la revelación es siempre de algo inalcanzable por completo para el conocimiento. Lo revelado no es una especie de objeto o instrumento susceptible de ser conocido en su totalidad, ya que nunca habrá un instrumento adecuado para ello. Entonces lo que revela el lenguaje es la revelación misma. En ello consiste fundamentalmente el arché del pensamiento como acontecimiento, es decir, en la posibilidad de concebir el mundo y producir conocimiento.

del lenguaje. Estos siete elementos o enunciados, permiten transitar por la teoría del lenguaje en particular y la teoría filosófica en general. En cada uno de estos temas prevalece una clara conexión con ideas expuestas en textos de diferentes periodos del pensamiento benjaminiano. Todo ello, visto con perspectiva, configura una especie de constelación cuyo centro neurálgico gira en torno al tema del lenguaje. Los dos últimos temas, esto es, los concernientes al lenguaje del arte y la simbólica del lenguaje, dan pie a un desarrollo ulterior más extenso en la medida que aparecen como elementos fundamentales de la teoría romántica de la obra de arte literaria y del concepto de crítica inherente a los románticos. Ambos aspectos son analizados y desarrollados extensamente en la tesis doctoral de Benjamin denominada El concepto de critica de arte en el Romanticismo alemán. 
La primera proposición, de las cuatro mencionadas, consiste en percibir cómo se mantiene, si tal cosa sucede, la teoría del lenguaje sobre el abismo, para lo cual Benjamin elabora una distinción inicial de carácter ontológico entre ser espiritual y ser lingüístico. Esta división es el supuesto teórico más importante del texto y su objetivo radica en dejar en claro que el lenguaje se extiende a todos los ámbitos de la manifestación espiritual humana, los cuales participan, de alguna manera, en el lenguaje: "no hay acontecimiento que pueda darse en la naturaleza, en la animada o inanimada, que no participe de algún modo en el lenguaje, pues a todo es esencial comunicar su contenido espiritual" ("Sobre el lenguaje en cuanto tal", 145). De inmediato Benjamin aclara que la palabra "lenguaje", tal como se emplea en esta afirmación, no es ninguna metáfora pues se refiere a un "conocimiento pleno" en la medida que comunica su ser espiritual en la expresión. En ello radica la afirmación con la que comienza este escrito: "toda manifestación de la vida espiritual humana puede ser entendida en tanto que un tipo de lenguaje" (144). Entonces, la diferencia establecida entre ser espiritual y lingüístico debe de interpretarse a partir de la certeza "de que no nos podamos imaginar una total ausencia de lenguaje en algo existente" (145), dado el caso, es decir, el de una existencia que careciese por completo de relación con el lenguaje, no estaríamos sino ante una idea: "pero una idea a la cual no se le puede sacar ningún partido ni siquiera en el ámbito de las ideas, cuyo perímetro lo marca la idea de Dios" (145). Lenguaje es pues, toda expresión que comunique contenidos espirituales. Pero estos contenidos espirituales que se comunican en el lenguaje no son el lenguaje mismo. Justo en ello estriba la diferencia entre el contenido espiritual y el lingüístico, el ser espiritual que se comunica en el lenguaje no es el lenguaje mismo, sino algo a distinguir respecto de él. Aquí aparece en su dimensión general la apuesta teórica de Benjamin tal como lo hemos mencionado antes:

entendida como hipótesis, la idea de que el ser espiritual de una cosa consiste en su lenguaje es el gran abismo en el que toda teoría del lenguaje amenaza caer, y la tarea de la teoría del lenguaje consiste en mantenerse sobre él suspendida. Así, la distinción establecida entre el ser espiritual y 
el ser lingüístico a través del cual aquel se comunica es la distinción más primordial en una teoría del lenguaje (146).

A esta afirmación Benjamin agrega una nota a pie de página, una nota que cuestiona directamente cierta trama filosófica, la cual dice: "¿O es más bien la tentación de situar la hipótesis al principio lo que conforma el abismo de todo filosofar?" (145) ¿Qué significa tal "tentación” filosófica? ¿Qué quiere decirnos Benjamin con esto? Él mismo está a punto de emprender su propia apuesta teórica que como tal no aspira sino a permanecer suspendida sobre el abismo, pero la tentación (Versuchung) de formular una hipótesis y situarla al principio da lugar al abismo de todo filosofar. Benjamin nos sitúa frente a una doble tensión abismal, una interior y otra exterior a la filosofía. La trama interior supone la "tentación" de la propia filosofía cuando trata de anteponer una hipótesis, es decir, una especie de metalenguaje cuyas deducciones pretenden encontrar un fundamento en aquello que no tiene fondo. Sin embargo, no se puede estar fuera del lenguaje, no se puede escapar de los contenidos espirituales que quedan tras su rastro. Benjamin no logrará escapar de esta aporía, la aporía del abismo filosófico, aquella que trata de encontrar fundamento en esa otra condición abismal interior a la propia filosofía, una condición que como veremos en seguida, solo es posible aceptar si se asume como principio condicionante de toda hipótesis filosófica.

En principio la trama externa de toda filosofía del lenguaje trata estrictamente de formular una teoría sobre el lenguaje abismal. El texto de Benjamin, como sucede con cualquier teoría, está orientado hacia esta trama externa que como hemos comentado antes, radica en la descripción de una caída que supone que la filosofía debe de asumir una paradoja que no es otra que la surgida de la distinción entre ser espiritual y ser lingüístico. Desde esta exterioridad del lenguaje ha quedado formulada la diferencia entre ser lingüístico y espiritual como si se tratara de una tercera lengua. ${ }^{4}$ En ella el lenguaje extiende su existencia, se

${ }^{4}$ Jacques Derrida plantea la noción de tercera lengua a partir del análisis de una carta de Gershom Scholem dirigida a Franz Rosensweig en 1926. En la carta Scholem expone su preocupación respecto al uso del hebreo, la lengua sagrada de las escrituras, como lengua secular. El conflicto no es otro que la "actualización de la lengua hebrai- 
manifiesta en la espiritualidad humana de la cual el lenguaje es inherente, y de ahí se extiende a todos los demás ámbitos. De esta manera no existen cosas ni acontecimientos de la naturaleza animada o inanimada que no participen en el lenguaje, ya que a todo es esencial comunicar su contenido espiritual. Por tal motivo es imposible pensar o imaginar algo fuera del lenguaje, algo que no comunique su "ser espiritual en la expresión". Aquí nace la paradoja que supone situarse fuera de él. Salir del lenguaje valiéndose de los medios lingüísticos como sucede en la teoría; ahí mismo surge la otra paradoja aún más radical, "tan profunda como inconcebible" ya presente en el doble sentido de la palabra logos, aquello que para Benjamin debe encontrar cierta "solución" en la teoría sin que los efectos de la paradoja en cuanto tal queden superados del todo, siempre que se asuma como hipótesis que se trata de algo "irresoluble cuando nos la encontramos al principio" (146). En este sentido se puede decir que Benjamin tiene que concebir un entramado teórico al referir una especie de tercera lengua; a ello alude la idea de un "lenguaje general" (Sprache überhaupt) más allá de toda división posible, más allá de la separación entre el contenido espiritual y lingüístico, que permita transitar de la aporía, como tal irresoluble e intransitable, a la potencia intelectiva que impulsa al pensamiento y por lo tanto a la teoría.

El fundamento de la teoría tiene que asumir la paradoja del lenguaje en general como hipótesis y con ello se conmina a la propia teoría a adoptar cierta performatividad. De esto se desprende la segunda proposición. Benjamin se pregunta: ¿qué comunica el lenguaje? La respuesta coincide plenamente con la "diferencia" antes mencionada: el lenguaje comunica "el ser espiritual que le corresponde" (146). Pero este "ser" no se comunica "en" el lenguaje, sino "mediante" el lenguaje. Desde este momento la comunicación es un tema de la pluralidad de las lenguas,

ca" (Historia de una amistad, 17). Ante tal cuestión el lenguaje de la teoría puede verse como una especie de lenguaje que toma cierta perspectiva al diferenciar entre lenguaje sagrado y secular, como si se tratara de una tercera lengua, un elemento cuya intención no es otra que presentarse como elemento diferenciador y metalingüístico, y por tanto, como supuesto teórico: "La expresión tercera lengua nombraría más bien un elemento diferenciado y díferenciador, un medio que no sería stricto sensu lingüístico sino el medio de una experiencia de la lengua que, no siendo ni sagrada ni profana, permite el pasaje de la una a la otra - y decir la una y la otra, traducir la una en la otra, nombrar de la una a la otra" (Derrida, Los ojos de la lengua, 32). 
donde queda evidenciada la dificultad de la propia comunicación. El ser espiritual no puede ser igual al ser lingüístico. Esta "identidad" solo es posible en virtud de que el ser espiritual pueda ser comunicable:

Lo que en un ser espiritual es comunicable es su ser lingüístico. Así pues, el lenguaje comunica el ser lingüístico propio de cada cosa, mientras que su ser espiritual solo lo comunica en la medida en que está inmediatamente contenido en el ser lingüístico, en la medida en que es comunicable (146).

A la cuestión ¿qué comunica el lenguaje?, Benjamin responde específicamente: "cada lenguaje se comunica a sí mismo" (146). A través de este punto se pueden destacar dos aspectos fundamentales en la idea de lenguaje: lo medial y el carácter fundamentalmente mágico e infinito del lenguaje. No solo el lenguaje "se" comunica a sí mismo sino “en" sí mismo, esto pone énfasis en su carácter de medio de la comunicación, de manera que

lo medial, que es la inmediatez de toda comunicación espiritual, es pues el problema fundamental de la teoría del lenguaje; y si se considera mágica a esta peculiar inmediatez, el problema primigenio del lenguaje es su magia. Claro que, al mismo tiempo, el hablar de la magia del lenguaje nos remite a otra cosa: su infinitud (147).

Lo anterior tiene que ver con la inmediatez, siempre que se tome en cuenta que mediante el lenguaje no se comunica nada, es decir: "lo que se comunica en el lenguaje no puede ser medido o limitado a partir o de fuera, por lo que todo lenguaje posee su única e inconmensurable infinitud. Y es que su ser lingüístico, y no sus contenidos verbales, le marca su límite" (147). Mientras el ser lingüístico marca los límites de la expresión (en ello radica su insuficiencia expresiva), los contenidos espirituales del lenguaje son infinitos, en razón de lo cual cobra sentido, entre otras cosas, la cuestión de la poesía y el poema mencionada por Benjamin en su texto dedicado a la tarea del traductor. Ahí Benjamin se pregunta: “¿Qué es lo que el poema comunica? Muy poco a quien lo entiende. Porque lo esencial en un poema no es la comunicación ni su mensaje" ("La tarea del traductor", 9). Si hay un ámbito donde se mues- 
tra claramente la infinitud de los "contenidos verbales", el problema primigenio del lenguaje, su radical contenido espiritual, es en el poema, eso que ofrece su espacio para dejar patente la infinitud de aquello que lo materializa. El poema muestra la infinitud espiritual del lenguaje al tiempo que transgrede los límites del ser lingüístico. Si en lugar del poema nos centramos en la figura del poeta como instancia generativa, no resulta sino pertinente analizar lo que Benjamin dice sobre la capacidad nominativa del hombre que es el tema que le ocupa de inmediato.

La tercera proposición concierne, entonces, a la capacidad nominativa del hombre. Así como se ha comentado antes que el ser lingüístico de las cosas es su lenguaje, ello se puede hacer extensivo a una perspectiva propiamente antropológica, esto es, según Benjamin: "el ser lingüístico del hombre es su lenguaje" ("Sobre el lenguaje como tal", 147). Esta afirmación queda explicitada del siguiente modo: el hombre comunica su propio ser espiritual en su lenguaje, en este caso "el lenguaje del hombre habla en las palabras" comunicando su ser espiritual, en la medida de lo comunicable al dar nombre a las cosas. De este modo es posible conocer otros lenguajes más allá del lenguaje humano, pero aceptando que no conocemos otro lenguaje "denominador" que no sea el del hombre. De este modo queda establecida una diferencia tan sutil como determinante: "al identificar el lenguaje denominador con el lenguaje en cuanto tal, la teoría del lenguaje se priva de los conocimientos más profundos. Por tanto, el ser lingüistico del hombre consiste en que este da nombre a las cosas" (147; cursivas mías). La teoría del lenguaje no debe de olvidar la diferenciación de estas dos instancias: el ser lingüístico del hombre consiste en "dar" nombre a las cosas; por otra parte, la entidad espiritual del lenguaje no debe ceñirse a tal actividad nominadora, sino permanecer como aquello que supone en sí lo no-nominado pero susceptible de serlo, permaneciendo entonces como entidad desconocida, pero no ajena al conocimiento ni al arte.

Paralelamente a la diferencia entre el ser lingüístico y espiritual, Benjamin propone una diferencia en lo relativo a la comunicación: el hombre comunica su ser espiritual "en" los nombres, no "mediante" ellos, "quien crea que el hombre comunica su ser espiritual mediante los nombres no puede en modo alguno suponer que es su ser espiritual lo que comunica, pues eso no sucede mediante nombres de cosas, 
mediante palabras mediante las cuales designa a una cosa" (148). Esta creencia es lo característico de la "concepción burguesa" del lenguaje, la cual da por hecho que el ser humano comunica una cosa usando la palabra como instrumento de la comunicación: su objeto es la cosa y su destinatario el ser humano. Frente a esto la idea del lenguaje de Benjamin antepondrá persistentemente la idea de un lenguaje mágico o místico que "no conoce instrumento, no conoce objeto ni destinatario de la comunicación. De acuerdo con ella, en el nombre el ser espiritual del ser humano se comunica en Dios" (148; cursivas mías). Para decirlo en su expresión más directa: Sprache ist Namen, el lenguaje es nombre. Sprache es a la vez lengua y lenguaje (en su interior, el término alemán guarda este doble significado). No es suficiente decir que la lengua es o consiste en nombres. Hablar es nombrar, es llamar. Hay dos instancias inherentes a esta concepción como ya lo hemos visto. En primer lugar el nombre "es la esencia más interior al lenguaje" (148), el nombre hace coincidir completamente el lenguaje en cuanto tal en el ser espiritual del hombre; y solo por eso el ser espiritual del hombre es el único de los seres espirituales comunicable por completo. Esto deja patente la diferencia entre el lenguaje humano y el lenguaje de las cosas. Como el ser espiritual del hombre es el mismo lenguaje, el hombre no se puede comunicar mediante el lenguaje, sino solo en él. De otro modo caeríamos en el equívoco de ver al lenguaje como instrumento y al nombre como medio de su ser espiritual. El lenguaje en cuanto tal, es decir, en cuanto entidad espiritual es el "núcleo" intensivo del lenguaje, y el hombre es quien da nombres restituyéndose de la decadencia instrumental, pues desde él habla el lenguaje puro. Justo en ello radica la segunda instancia: el lenguaje es el ser que se comunica en el nombre. El nombre es la auténtica "llamada" del lenguaje. El hombre es quien invoca y convoca a los nombres, el que hace el llamado. Así es como el hombre deviene el "señor de la naturaleza", pues da nombre a las cosas, "mediante el ser lingüístico de las cosas, llega el hombre a conocerlas a partir de sí mismo: a saber, en el nombre. La Creación de Dios queda completa al recibir las cosas su nombre del hombre, desde el cual, en el nombre, solo habla el lenguaje" (149). Planteadas las cosas de este modo, Benjamin especifica un aspecto más respecto al nombre: "se puede por tanto calificar el nombre de lenguaje del lenguaje (si el genitivo no indica la rela- 
ción de instrumento, sino la de medio), y en este sentido el ser humano, ya que habla en el nombre, es también el hablante del lenguaje, su único hablante" (149). Este gesto, esta manera de plantear la cuestión, es lo que configura tanto un conocimiento como un principio metafísico común a muchas lenguas, e instituye un elemento teórico fundamental: Sprache ist Namen. En él hay un llamado a la esencia del lenguaje y de la lengua. Él contiene en una palabra, un nombre, el nombre de nombre. El ser del lenguaje no reside en el verbo, en el sentido gramatical, en los atributos, o en la proposición. Aquello que no tiene la forma gramatical del nombre (que no es aquí el sustantivo sino la referencia nominal) no pertenece al lenguaje sino en la medida en que todos los elementos del lenguaje se dejan nominalizar: el verbo, el adjetivo, la preposición, el adverbio. El nombre no tiene el valor nominal del sustantivo, él significa el poder de nombrar, de llamar en general. Sprache ist Namen, el lenguaje es nombre, invoca la esencia del lenguaje y actualiza la ponencia nominal de la lengua. Tras lo cual puede decirse, como lo ha dicho Jacques Derrida respecto de Scholem:

en el nombre es donde se oculta la potencia del lenguaje, en él está sellado el abismo que él encierra. Hay entonces un poder del lenguaje, a la vez una dynamis, una virtualidad disfrazada, una potencialidad que podemos hacer pasar, o no, al acto; ella está escondida, oculta, adormecida. La cara oculta del lenguaje, su potencia. Esta potencialidad es también un poder (Match), una eficacia propia que actúa por ella misma, de manera casi autónoma, sin la iniciativa de y más allá del control de los sujetos hablantes ("Los ojos de la lengua", 49-50).

Esta manera de situarse fuera del control del poder subjetivo se debe sobre todo a que el poder mágico del nombre produce poderes y llamados reales, imposibles de ser manipulados por el hombre. El nombre esconde, guarda en su potencia, un poder de manifestación y ocultación, de revelación y cifra hermética. Y lo que el nombre esconde es el abismo que está encerrado en él. Invocar un nombre es hacer un llamado a su apertura, es encontrar en él no ya una cosa, sino algo así como una realidad abismal, el abismo como la cosa misma. Ante tal poder, una vez despertado, no queda sino reconocer la imposibilidad del sujeto de man- 
tener el control. Los nombres son trascendentes y más poderosos que los hombres quienes en su existencia, en su finitud, en su mortalidad, los invoca. Por tal razón la mayoría de los hombres (tal es la confesión de Gershom Scholem a Franz Rosenzweig), caminan sin saberlo como ciegos sobre un abismo. El hombre al invocar un nombre abre los poderes que ellos ocultan y hace un llamado a la esencia abismal del lenguaje.

Una vez mostrado el carácter abismal del lenguaje y habiendo reformulado, mediante la teoría del lenguaje, el principio que considera lingüístico tanto el ser espiritual del hombre como el de las cosas, en la medida que este es comunicable, podemos abordar el último tema en cuestión. Benjamin dirige su atención a la densidad y gradación en el proceso de comunicación al interior del ser espiritual del lenguaje: "Las diferencias de las lenguas son diferencias de medios, los cuales se diferencian a su vez por su densidad, gradualmente; y esto en el doble sentido de la densidad de lo comunicante (denominador) y la densidad de lo comunicable (nombre) precisamente en la comunicación" ("Sobre el lenguaje como tal", 150; cursivas mías). Las implicaciones de este doble criterio, el de la densidad y la gradualidad, tiene efectos principalmente dentro de dos órdenes, el metafísico y el teológico. Para detectar tales efectos Benjamin vuelve a la equiparación que se ha empleado desde un principio como criterio fundamental:

la equiparación comparativa del ser espiritual con el lingüístico, que solo conoce diferencias graduales, tiene sin duda como consecuencia para la metafísica del lenguaje la gradación del ser espiritual. Dicha gradación, que tiene lugar en el interior mismo del ser espiritual, no puede subsumirse bajo una categoría superior, por lo que conduce a la gradación de todos los seres espirituales y lingüísticos desde el punto de vista de la existencia o del ser (150).

En lo anterior podemos leer claramente que Benjamin asume, en este momento, una perspectiva distinta a la de una caída del lenguaje. Tal parece que ahora se adopta otro criterio. Al interior de la entidad espiritual del lenguaje la gradación no permanece subsumida a una categoría superior. Este aparente cambio de orientación no clausura o limita los efectos de la idea del lenguaje sustraída de la interpretación bíblica, por 
el contrario, despeja el camino de la reflexión filosófica para profundizar en la teología mediante la filosofía de la religión:

La equiparación del ser espiritual con el ser lingüístico es tan relevante metafísicamente para las teorías del lenguaje porque conduce al concepto que una y otra vez se ha elevado como por sí mismo en el centro de la filosofía del lenguaje y que ha conformado la más estrecha conexión de dicha filosofía con la filosofía de la religión. Nos estamos refiriendo al concepto de revelación (150).

Para concebir el significado de esto en su dimensión más justa, habrá que avanzar con mucho cuidado a través de la descripción de Benjamin. En primer lugar hay una idea que nos remite directamente a cierto antagonismo dentro de las concepciones místicas del lenguaje. Hay que recordar las palabras de Scholem al mencionar que todo místico de la lengua consagra su activad a buscar la cara interior del lenguaje, la cara oculta. Y no es otra cosa la observada por Benjamin al interior de la expresión lingüística: "Dentro de toda configuración lingüística impera el antagonismo de dicho y decible con indecible y no dicho. Al observar este antagonismo, en la perspectiva de lo indecible puede verse al mismo tiempo el último ser espiritual" (150). Ahora bien, aunque el hombre logre cierta comunidad con Dios por medio de su capacidad de dar nombres, por su capacidad de llamar e invocar, el ser humano se encuentra también conectado con el lenguaje de las cosas. Dado que la palabra humana es el nombre mismo de las cosas, no podrá reaparecer la idea (propia de la concepción burguesa del lenguaje) de que la palabra solo guarda una relación accidental con la cosa, de que la palabra es signo de las cosas o que es un signo de un acontecimiento que se estableció por convención. El lenguaje nunca da meros signos. Pero el tema no se resuelve simplemente descartando una teoría por otra, el "rechazo de la teoría burguesa del lenguaje mediante la teoría mística del lenguaje sin duda es equívoco" (155). ¿A qué se refiere tal equivocidad? Es como si se tratara, en algún grado, de cierto despropósito rechazar una teoría, la burguesa, mediante la teoría mística del lenguaje. Este no es el momento de la jerarquización. ¿En qué radica entonces eso que parece un "despropósito"? La perspectiva asumida por Benjamin 
en este momento es la de una realidad totalmente existencial, no subsumida bajo ninguna categoría superior en lo relativo a la gradación de todos los seres espirituales y lingüísticos, y esa manera de ver las cosas no permite marcar claramente la preeminencia de una teoría sobre otra. Estamos entonces en un nivel de total paroxismo, donde no hay cabida para ningún criterio o jerarquía respecto a cualesquiera supuesto teórico o filosófico. Esta virtualidad del lenguaje queda evidenciada cuando Benjamin define la teoría mística del lenguaje y cómo esta no escapa al dilema que finalmente resplandece oculto en el lenguaje, visto desde la perspectiva de la existencia:

De acuerdo con esta [la teoría mística del lenguaje], la palabra es la esencia de la cosa, algo que es incorrecto porque la cosa no tiene ninguna palabra, habiéndose creado a partir justamente de la idea de Dios y siendo en su nombre conocida según palabra humana. Este conocimiento de la cosa no es creación espontánea: no sucede a partir del lenguaje de forma ilimitada e infinita como él sí sucede; sino que el nombre que el hombre da a las cosas se basa en cómo ella se comunica al hombre. Así pues, en el nombre, la palabra divina ya no sigue creando; concibe parcialmente pero solo al lenguaje. De modo que esta concepción se dirige al lenguaje de las cosas, a partir de las cuales la palabra divina resplandece en la magia muda de la naturaleza (155).

Esta confusión, inversión o virtualidad del lenguaje es muy importante a lo largo de la obra de Benjamin. Parece que se ha transgredido todo orden jerárquico, toda consecuencia entre las esencias y las apariencias. Por tal motivo la cosa no tiene ninguna palabra sino que es conocida en su nombre por la palabra humana. La palabra divina deja de crear en aquello propio del hombre, que como lo hemos visto, es una especie de encadenamiento entre su capacidad nominativa, su capacidad de invocar, de dar nombre y su entidad lingüística como aquello donde se dirime de manera más instrumental la lengua. Todo esto no supone en sí mismo ningún orden jerárquico, en ello radica el equívoco de algunas teorías místicas del lenguaje, en ver en la palabra la esencia de las cosas. Las cosas, al ser creadas por idea de Dios, solo pueden ser conocidas por el nombre que el hombre les ha asignado. No se abandona, entonces, el orden místico del lenguaje. Benjamin no cambia de 
perspectiva, solo especifica: ahí donde la palabra divina ha dejado de crear queda la mudez de las cosas y de la naturaleza. Ahí mismo permanece, en potencia, la palabra divina cuyo resplandor solo es concebible mediante su revelación. Entonces ¿cuál es el sentido de esta revelación? Antes mencionamos el significado fundamental, el arché de la revelación, como algo que se muestra inalcanzable a los medios cognitivos del hombre. Lo revelado no es un objeto o un instrumento susceptible de conocerse en su totalidad ya que nunca habrá un instrumento adecuado para ello. Lo que devela el lenguaje es el develamiento mismo, y en ello radica fundamentalmente el arché como acontecimiento de apertura del mundo y del conocimiento.

Finalmente los elementos fundamentales de la teoría del lenguaje de Benjamin, la entidad espiritual y lingüística, se tocan inextricablemente en la revelación, pues ella muestra que toda palabra y todo conocimiento humano encuentran fundamento en una apertura que los trasciende infinitamente; simultáneamente esta apertura no concierne sino al lenguaje mismo, a su posibilidad y su existencia. La revelación es el lenguaje en cuanto tal, sin teorías, sin divisiones, sin distinciones. En razón de ello la tarea de la teoría no es otra sino concebir sus propias posibilidades de acceder al terreno místico de la lengua, ahí donde está su fundamento más profundo (en el fondo imposible del abismo). La tarea de la teoría consiste en dejarnos transitar sobre la esencia abismal del lenguaje. En ello radica la posibilidad de permanecer sobre el abismo, no como ciegos que caminan inconscientes sobre él ante la inminente caída, más bien pendientes de aquello mediante lo cual sea posible ver (en su parcialidad, en su mortal precariedad, en su frágil constructo intelectual) la cara oculta de la lengua.

\section{REFERENCIAS}

Agamben, G., La potencia del pensamiento, Buenos Aires, Adriana Hidalgo, 2007.

Benjamin, Walter, Obras. Libro I. Vol.1, El concepto de crítica de arte en el romanticismo alemán, Madrid, Abada, 2007. 
Benjamin, Walter, Obras. Libro II. Vol. 1, "Sobre el lenguaje en cuanto tal y sobre el lenguaje del hombre", en Primeros trabajos de crítica de la educación y de la cultura, Madrid, Abada, 2007.

Benjamin, Walter, Obras. Libro IV. Vol.1, "La tarea del traductor", en Charles Baudelaire, "Tableaux parisiens", Madrid, Abada Editores, 2010.

Benjamin, Walter, Gesammelte Schriften, II/1. Frühe Arbeiten zur Bildungs und Kulturkritik. Metaphysisch geschichtsphilosophische Studien. Literarische und ästhetische Essays, Frankfurt/M: Suhrkamp Verlag, 1991 [Obras, II/1, Madrid, Abada, 2007].

Benjamin, Walter, Gesammelte Briefe, Bd. 1, Frankfurt/M, Suhrkamp, 1995.

Benjamin, Walter, "Sobre el programa de la filosofía venidera", en Para una crítica de la violencia y otros ensayos, Madrid, Taurus, 1991.

Derrida, J., "Los ojos de la lengua", Córdoba, Año XIX, No 24, noviembre, 2010.

Mosès, S., El ángel de la historia, Valencia, Pretextos, 1997.

Scholem, G., Lenguajes y Cábala, Madrid, Siruela, 2006.

Scholem, G., Historia de una amistad, Barcelona, Península, 1987. 